\title{
Investigation the Effect of Water Ratio and Additives on the Properties of Castable Refractory
}

\author{
Fatih Kabadayi \\ Faculty of Chemistry-Metallurgy, Metallurgical and Materials Engineering, \\ Yildiz Technical University, Istanbul, Turkey \\ E-mail: fatihkabadayi92@gmail.com \\ Sezgin Yasa \\ Faculty of Chemistry-Metallurgy, Metallurgical and Materials Engineering, \\ Yildiz Technical University, Istanbul, Turkey \\ E-mail: sezgin.yasa92@gmail.com \\ Mustafa Cigdem \\ Faculty of Chemistry-Metallurgy, Metallurgical and Materials Engineering, \\ Yildiz Technical University, Istanbul, Turkey \\ E-mail: cigdem@yildiz.edu.tr
}

\begin{abstract}
Castable refractories are resistant to the high temperatures just like the other refractories. Significant progress has been made after calcium aluminate cement has been started using in castable refractory technology. The properties of these refractories are vastly dependent on the selected mixture and the amount of water added. In this study, the effects of water amount and additives on setting time, fluidity and mechanical properties was investigated by using $25 \% \mathrm{CAC}$ (calcium aluminate cement) and fused silica. As a result of the studies, it was observed that the as the amount of water decreased, the setting time is also decreased, the mechanical properties improved and the fluidity was variable depending to the composition.
\end{abstract}

Keywords: CAC, castable refractories, fused silica

DOI: $10.7176 / \mathrm{JSTR} / 5-4-07$

\section{Introduction}

Calcium aluminate cements are one of the most widely used binders in refractory concrete production [1, 2]. Calcium aluminate based concretes have faster settling times than Portland cements [2]. CAC has very good resistance to corrosion and is a high performance cement due to its low setting time and high wear resistance. CAC is used for repairing on runways, on motorways on interior and exterior surfaces of buildings [3].

The castable refractories are formulated by mixing aggregate with various binders, fillers and with other additives. The aggregates have the highest percentage in the refractory formula and form the skeleton of the refractory. The choice of the aggregate to be used in castable refractories is made according to the desired physical and chemical properties. For the mixture, more than one type of aggregate can be used as well as just one $[4,5]$.

The most important characteristics of the castable refractories are the particle size distribution of the aggregate and binder used, setting time, mechanical strength, bonding type and shrinkage ratio. The bond formed can be hydraulic or chemical and affect the behavior of the material at high temperatures.

In the last 10 years, the use of hydraulically bonded castable refractories has increased rapidly due to the easiness of the application of the products for high temperature applications. Application of these refractories is carried out in the field by mixing the pre-prepared powder with water. Then, it is left to harden. The water used in the mixture is added as a means for the occurrence of hydraulic bonds. Excessive addition of water causes higher shrinkage and lower mechanical and corrosion resistance after sintering [6].

There are two ways to reduce the ratio of water used in castable refractories:

- Adding special blended chemicals to increase the fluidity

- Adding very fine size reactive powders to replace the cement 
These fine reactive powders reduce the porosity by filling the gaps between the coarse grains normally filled with water when used with suitable dispersants [7].

In the first attempts to improve the strength by lowering the water ratio, the result was unsuccessful, since sufficient mechanical strength could not be achieved in mixtures with a cement ratio below $10 \%$. It was first mentioned in a French patent in 1969 that the cold and hot strength characteristics of the castable refractories, whose cement content did not exceed 5-8\%, were very good. Reducing the cement ratio without reducing the mechanical strength was achieved by adding approximately $2.5-4 \%$ fine grained clay minerals and between $0.01-0.3 \%$ plasticizer. [8]

In refractory castables, the relation between water ratio-additives and setting time is an issue to be examined. In refractory castables curing and setting conditions are important matter for strength improvement. Insufficient strength before sintering may cause damages in refractory during heating up process [9]. On the other hand, from the beginning of the process to the end, 20-30\% of the total time is wasted while waiting for setting and curing. Any reduction in curing time or setting time brings an economical value [10].

In this study, fused silica-calcium aluminate mixture and additions in different ratios were used as refractory raw materials. Various mixtures were casted into cube molds and pre and post sintering strengths, setting times, fluidity and shrinkage rates were examined. Finally, the optimum parameters for desired properties were investigated.

\section{Experimental Work}

In the study, mixtures in the proportions of table 1 and table 2 were prepared. It was mixed in the rotary drum for about 15 minutes to ensure a homogeneous mixture of powders. The powders were then mixed with water or water+plasticizer mixture and prepared for casting. After adequate mixing, casting performed on molds $3 \times 3 \times 3 \mathrm{~cm}[ \pm 2 \mathrm{~mm}]$. The fluidity of the mixture in table 1 was observed during casting. In order to make filling easier and let the air bubbles go away, vibration applied on the molds for 3-4 min. From the moment the powders were mixed with water, setting time was observed to be approximate. After casting, the samples were cured at room temperature for about 120 hours. At the end of this period, compressive strength test is performed on the mixtures given in table 1 before sintering. Additionally, mixtures given in table 2 are heated up in electric resistance furnace until $1250^{\circ} \mathrm{C}$ with the speed of $10^{\circ} \mathrm{C} / \mathrm{min}$ and held for $5 \mathrm{~h}$. Left for cooling in the furnace and then, shrinkage rates and compressive strengths are investigated. The shape of the test specimens of compressive strength and shrinkage test are given in figure 1 .

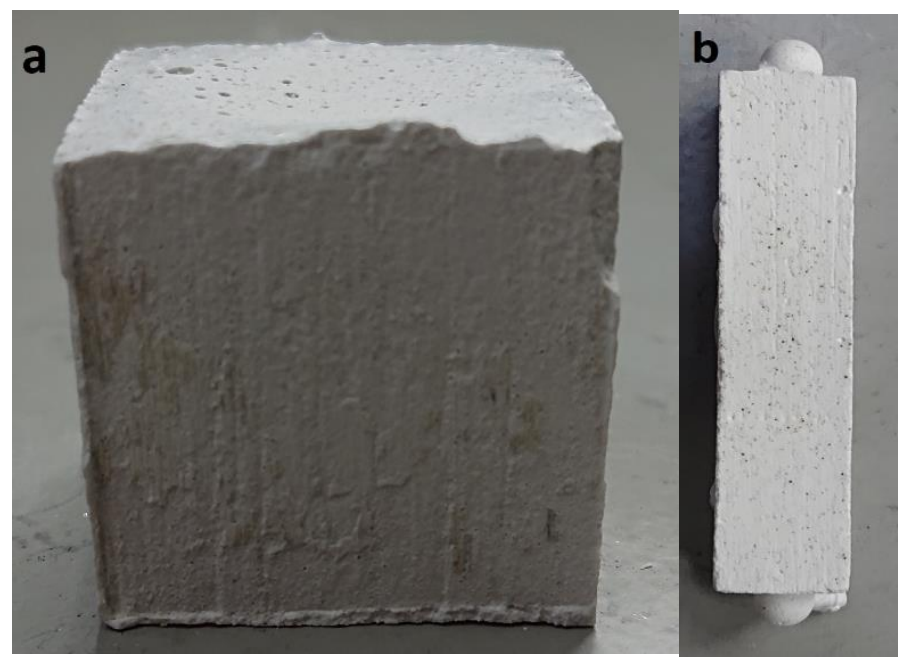

Figure 1. Shape of the specimens: a) compressive test, b) shrinkage test 
Table 1. Composition of the specimens measured for cold compressive strength

\begin{tabular}{|c|c|c|c|c|c|c|c|}
\hline \multirow{2}{*}{$\begin{array}{c}\text { Experiment } \\
\text { Number }\end{array}$} & \multirow{2}{*}{$\begin{array}{c}\text { Aggregate } \\
\text { Fused } \\
\text { Silica }[\mathrm{g}]\end{array}$} & \multirow{2}{*}{$\begin{array}{c}\text { Binder } \\
\text { Secar } \\
71[\mathrm{~g}] \\
\end{array}$} & \multicolumn{4}{|c|}{ Additives } & \multirow{2}{*}{$\begin{array}{c}\text { Water } \\
{[\%]}\end{array}$} \\
\hline & & & $\begin{array}{c}\text { Electrolyte } \\
{[\mathrm{g}]}\end{array}$ & $\begin{array}{c}\mathrm{NaH}_{2} \mathrm{PO}_{4} \\
{[\mathrm{~g}]} \\
\end{array}$ & $\begin{array}{c}\mathrm{Li}_{2} \mathrm{CO}_{3} \\
{[\mathrm{~g}]} \\
\end{array}$ & $\begin{array}{c}\text { Plasticizer } \\
{[\mathrm{g}]}\end{array}$ & \\
\hline 1 & 74 & 25 & 1 & - & 0.02 & - & 40 \\
\hline 2 & 73 & 25 & - & 2 & 0.02 & - & 35 \\
\hline 3 & 75 & 25 & - & - & 0.02 & 0.5 & 30 \\
\hline 4 & 75 & 25 & - & - & 0.02 & 2 & 25 \\
\hline 5 & 75 & 25 & - & - & 0.02 & 3 & 20 \\
\hline 6 & 75 & 25 & - & - & 0.02 & 4 & 18 \\
\hline
\end{tabular}

Table 2. Composition of the specimens measured for cold compressive strength after sintering

\begin{tabular}{|c|c|c|c|c|c|c|c|}
\hline \multirow{2}{*}{$\begin{array}{c}\text { Experiment } \\
\text { Number }\end{array}$} & Aggregate & Binder & \multicolumn{4}{|c|}{ Additives } & Water \\
\cline { 2 - 7 } & $\begin{array}{c}\text { Fused } \\
\text { Silica }[\mathrm{g}]\end{array}$ & $\begin{array}{c}\text { Secar } \\
71[\mathrm{~g}]\end{array}$ & $\begin{array}{c}\text { Electrolyte } \\
{[\mathrm{g}]}\end{array}$ & $\begin{array}{c}\mathrm{NaH}_{2} \mathrm{PO}_{4} \\
{[\mathrm{~g}]}\end{array}$ & $\begin{array}{c}\mathrm{Li}_{2} \mathrm{CO}_{3} \\
{[\mathrm{~g}]}\end{array}$ & $\begin{array}{c}\text { Plasticizer } \\
{[\mathrm{g}]}\end{array}$ & \begin{tabular}{c} 
[\%] \\
\hline 7
\end{tabular} \\
74 & 25 & 1 & - & 0.02 & - & 40 \\
\hline 8 & 75 & 25 & - & - & 0.02 & 0.5 & 30 \\
\hline 9 & 75 & 25 & - & - & 0.02 & 3 & 20 \\
\hline
\end{tabular}

\section{Results and Discussion}

The results of the setting times, fluidity and compressive strength of the mixtures in table 1 and the results of the post-sintering pressings of the mixtures in table 2 are given below. Figure 2 shows a comparison of the fluidity observed during casting.

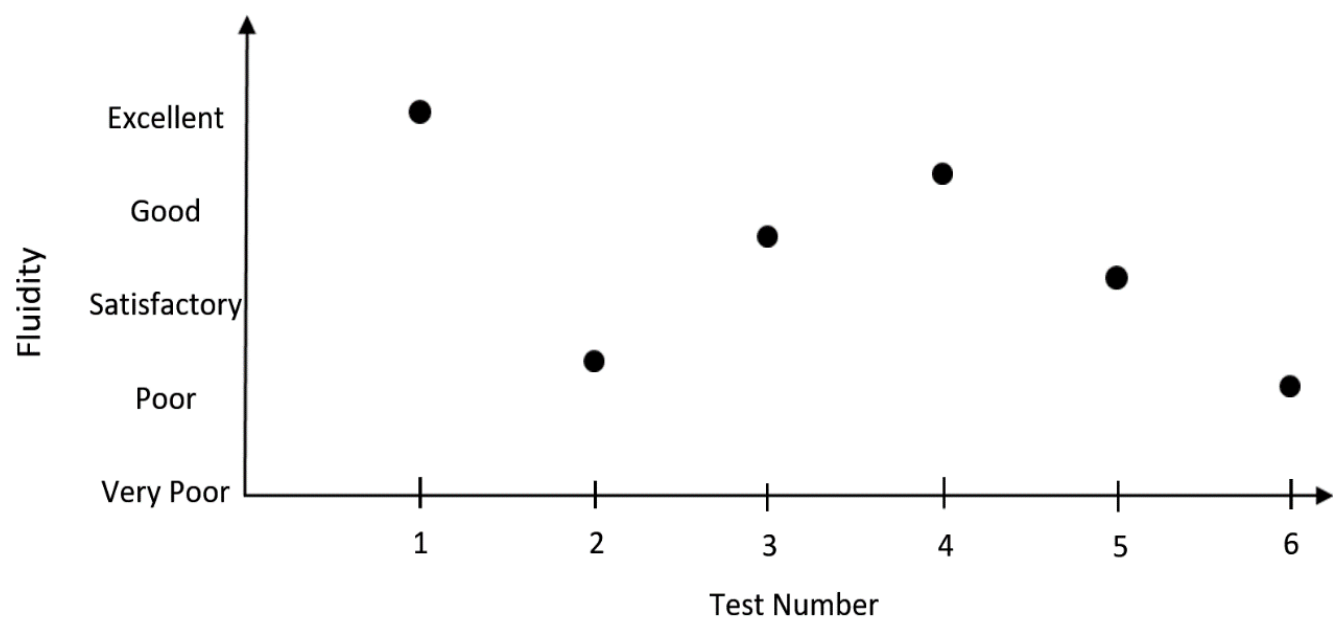

Figure 2. Fluidity comparison of the casts given in table 1.

As is evident from the graph, it can be clearly seen what the effect of the addition of plasticizer and the water ratio on the fluidity is. With the decrease in water ratio, it was observed that the castability is very 
low, especially with $35 \%$ water. Therefore, castings in which water were used less than $35 \%$ were made by adding plasticizer. It is noticed that the plasticizer improves castability in water up to $25 \%$. However, castability was difficult in mixtures 5 and 6 . the water contents of which were $25 \%$ and $20 \%$, respectively, even though higher plasticizer content.

The setting times of the mixtures in Table 1 are given in figure 3 .

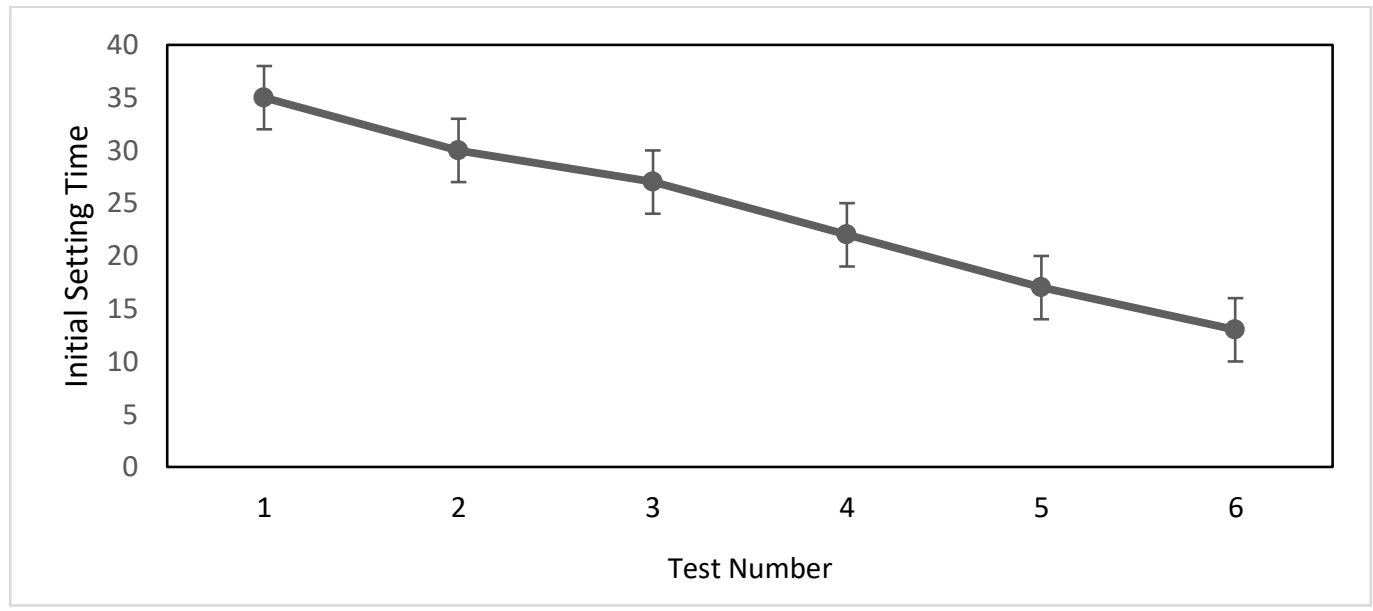

Figure 3. The setting times of the mixtures given in table 1.

Figure 3 shows that the setting times of the casts decreases with decreasing water ratio. It is not desirable to have a too short or too long setting time. Too short setting time causes not enough time for application. In addition, too long setting time causes a longer wait and such a situation causes a loss of time in applications requiring fast strength.

Figure 4 shows the pre-sintering test results of the samples the contents of which are given in table 1

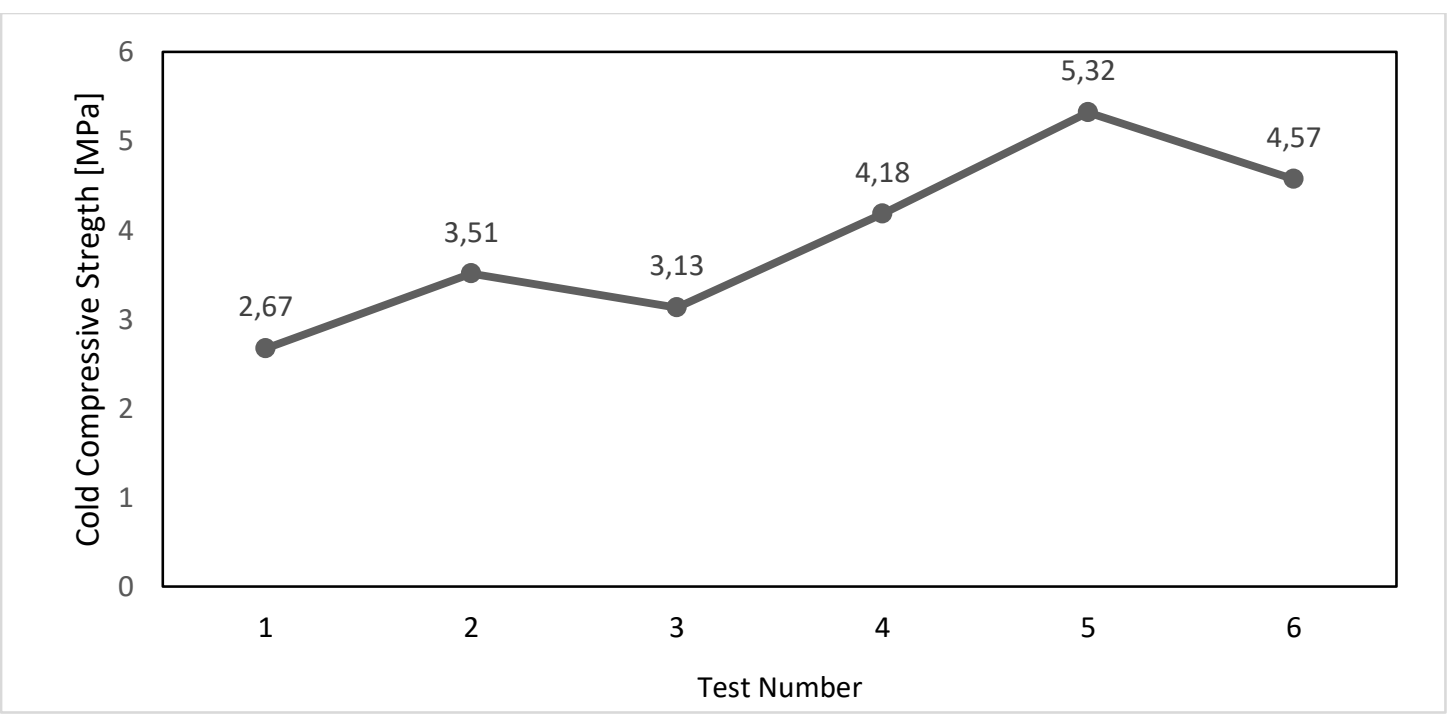

Figure 4. Compressive strengths of mixtures given in table 1.

As a result of the tests, the highest strength value was found to be $5.32 \mathrm{MPa}$ in the sample number 5 with a water ratio of $25 \%$. When the figure 4 is examined for compressive strength, it can be seen that the compressive strengths tend to increase with decreasing water ratio. The main reason for this is the decrease in porosity with the decrease in the amount of water. Figure 4 also shows that although the amount of water decreases, the strength decreases in the mixture 6. It is thought that this decrease in strength is due to the inability to form enough bonds between the powders at very low water ratios. Due to the use of a plasticizer, low water rates were achieved. It can be said that the plasticizer indirectly 
increases the strength in castable refractories thanks to this mechanism.

Figure 5 shows the comparison of the shrinkage ratio of shrinkage test specimens.

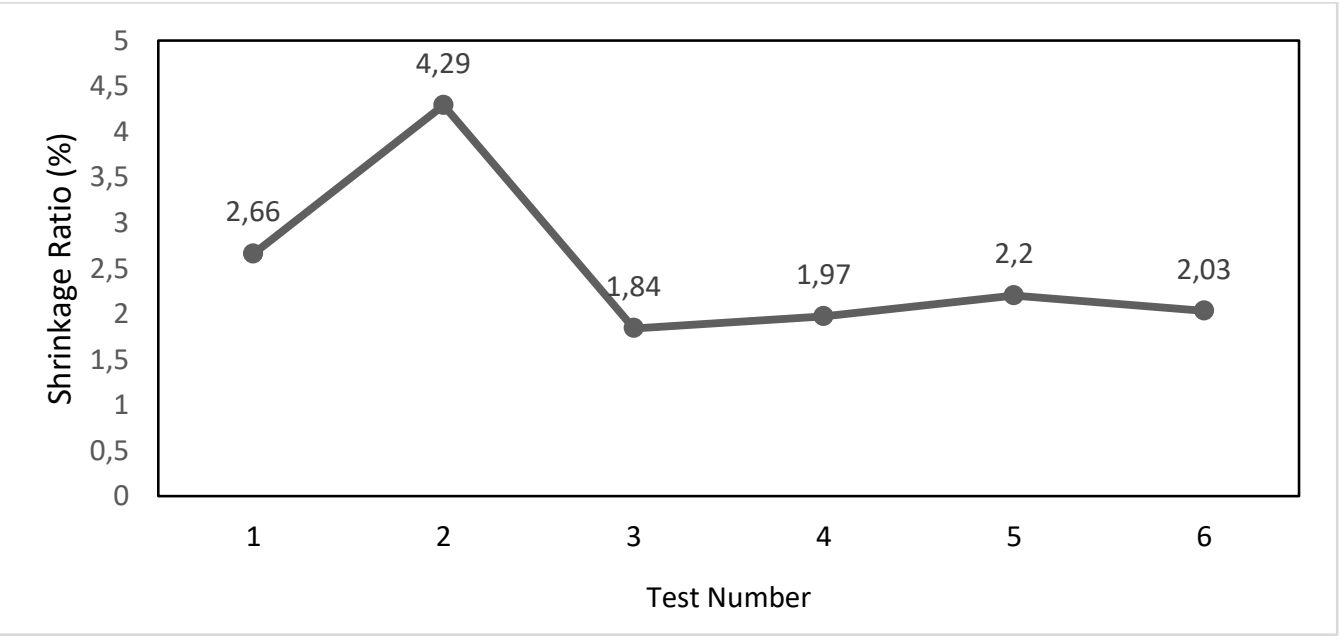

Figure 5. Shrinkage ratio of mixture given in table 1 after sintering.

Generally we can infer from figure 5 that shrinkage ratio decreases with decrease in water ratio. Below $30 \%$ water content, shrinkage ratio stayed almost constant. Shrinkage ratio is important parameter for castable refractories since high shrinkage ratio can cause cracks during heating up process as shown in figure 6 .

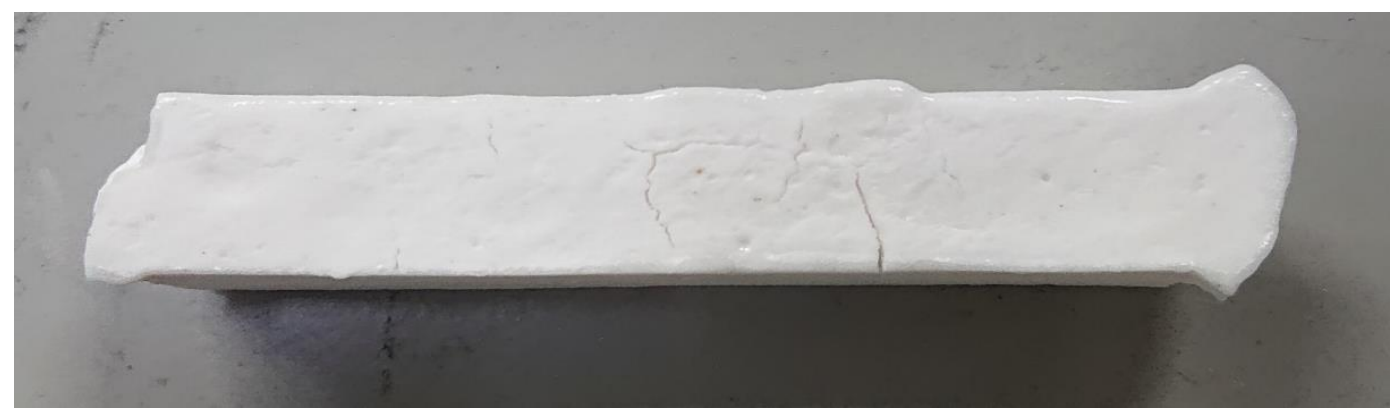

Figure 6. Cracks occurred in test number 2 during sintering process.

After sintering compressive strengths of specimens given in table 2 has been shown in figure 7 .

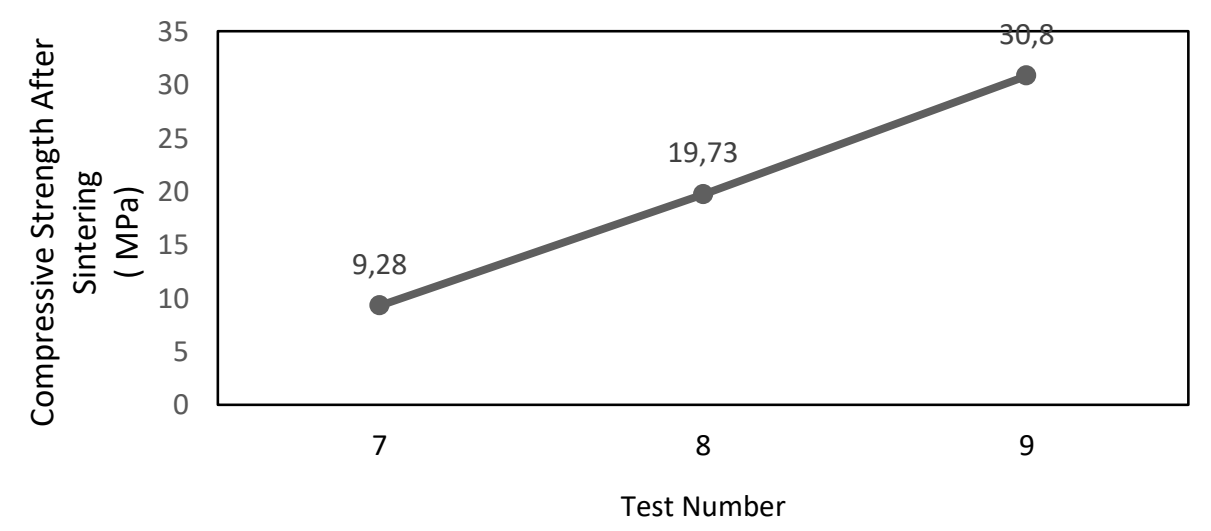

Figure 7. After sintering compressive strengths of mixture number 7, 8, 9 . 
Results of figure 7 proved that decreasing water ratio greatly increases the compressive strength after sintering. Water vaporizes during the sintering which leads to porosity. Low porosity affect mechanical strength positively. Therefore, we can clearly see the reason why mixture number 9 has greatest strength.

\section{Conclusion}

- With the decreasing water ratio, setting time decreases.

- Fluidity strongly depends on water ratio and additives.

- Pre-sintering compressive strength tend to increase with the decrease of water ratio.

- Sintering greatly improves the compressive strength in the low water content mixtures.

- Shrinkage ratio is affected by water content until $30 \%$ water ratio then it stays constant. High shrinkage ratio may cause cracks.

\section{Referances}

[1] Valentin Antonovič; et all.: (2013), The Effect of Temperature on the Formation of the Hydrated Calcium Aluminate Cement Structure, Procedia Engineering 57, 99 - 106

[2] Walter Gabriel Bareiro; et all.: (2018), The influence of alumina content on the chemical and mechanical behavior of refractory concretes fired at different temperatures, Construction and Building Materials 187, 1214-1223

[3] Mohamed Heikal; et all.: (2015), Physico-mechanical characteristics and durability of calcium aluminate blended cement subject to different aggressive media, Construction and Building Materials 78, 379-385

[4] Çetin Öztürk; et all.: (2014), The Effect of Various Alumina Based Agregates on Physical and Mechanical Properties of High Alumina Castable Refractory, AKU J. Sci. 025701, 1-8

[5] Charles A. Schacht: (2004), Refractories Handbook, USA

[6] Abílio P. Silva; et all:: (2012), Effect of particle size distribution and calcium aluminate cement on the rheological behaviour of all-alumina refractory castables, Powder Technology 226 (2012) $107-113$

[7] Florin Esanu; (2000), Self Flowing Refractory Castabes: Study Of The Hydraulic Bond And Ceramic Matrix Formation, Phd Thesis, The University of British Columbia, Department of Metals and Materials Engineering, Vancouver, Canada

[8] W.E. Lee, W. Vieira, S. Zhang, K.G. Ahari, H. Sarpoolaky \& C. Parr: (2001), Castable refractory concretes, International Materials Reviews, 46:3, 145-167,

[9] O. Krause, D. Cölle, H. Schaffhauser, D. Jahn: (2012), Setting Kinetics of High-dispersed Refractory Castables, Refractories WORLDFORUM 4, 81-88

[10] Parr, C.; et al.: (2007), Optimization of the hardening properties of refractory castables using nondestructive techniques to measure early age properties, Int. J. of Appl. Ceram. Technol. 4 [6] 524-534 